\title{
On the separation of barytes and strontia
}

\author{
Mr. J.D. Smith
}

To cite this article: Mr. J.D. Smith (1836) On the separation of barytes and strontia, Philosophical Magazine Series 3, 8:46, 259-261, DOI: 10.1080/14786443608648864

To link to this article: http://dx.doi.org/10.1080/14786443608648864

册 Published online: 01 Jun 2009.

Submit your article to this journal 준

LII Article views: 2

Q View related articles $₫$ 
of alcohol, and if the density of each two ounces of product as it is obtained be taken, it will be observed that this density passes gradually from 0.780 to 0.788 and 0.798 , and afterwards remains constantly at the last-mentioned density, which is exactly that of the alcohol employed. If the operation be properly conducted, an unlimited quantity of alcohol uny be converted into æther, provided that the sulphuric acid does not change. The distilled liquor is formed of two distinct fluids; the upper one is ather, containing a little water and alcohol; the lower one is water, with a little alcohol and æther. Its weight is nearly equal to that of the alcoliol employed, and it is composed of

$$
\begin{aligned}
& \text { Ather } \ldots \ldots \ldots \ldots \\
& \text { Alcohol......... } \\
& \text { Water ......... } 18 \\
& 17-100
\end{aligned}
$$

If into six ounces of concentrated sulphuric acid six ounces of pure alcohol are suffered to flow gradually, a product of constant density is not obtained until the sulphuric acid has taken its proportion of water. Take, on the contrary, three ounces of sulphuric acid and two ounces of water, and let alcohol be added, drop by drop ; the first two ounces distilled are merely spirit, if wine of specitic gravity $\mathbf{0 . 9 2 6}$, containing scarcely a trace of ather. The density decreases until the quantity of water of the sulphuric acid is reduced to its proportion, and the product of the distillation has acquired the density of the alcohol.

If concentrated sulphuric acid be added to anhydrous alcohol in excess, pure alcohol distils at first; but when the temperature reaches nearly $260^{\circ}$, the first traces of æther begin to appear; the production of æther is at its maximum between $284^{\circ}$ and $302^{\circ}$.

It results, from the preceding observations, that alcohol, when in contact with sulphuric acid, is converted into 2 ther and water at a temperature of about $284^{\circ}$. A great number of analogous decompositions and combinations are known, which may be attributed entirely to the influence of the contact of bodies. The most remarkable example of this kind is that of the conversion of oxygenated water into water and oxygen, by the slightest trace of the peroxide of manganese and some other substances. The decomposition of sugar into alcohol and carbonic acid, the oxidizement of alcohol when it is changed into vinegar, are phænomena of the same kind; and so also is the conversion of starch and sugar by means of sulphuric acid. M. Mitscherlich, observing that in the preparation of carburetted hydrogen by means of sulphuric acid and alcohol water is formed at the same time, attributes this decomposition of alcohol to the influence of mere contact, and not to the affinity of sulphuric acid for water.-Journal de Pharmacie, Juin 1835.

\section{ON THE SEPARATION OF BARY'IES AND STRONTIA.-BY}

MR. J. D. SMITH.

The great analogy existing between the salts of barytes and strontia, may render an observation on the difference of solubility in water of 
their chromates worthy of notice; and the more so, as it adds one to the few methods already devised for the analysis of substances containing both these earths. I had remarked some time before, that when a solution of neutral chromate of potash was added to one of muriate of strontia considerably diluted, no precipitation took place until the mixed solutions were boiled, and even then that a large quantity of strontia was still held in solution; whilst, on the other hand, the action of the neutral chromate of potash on a solution of muriate of barytes was widely different ; for let the solution of barytes be ever so largely diluted, yet chromate of potash invariably produced precipitation; so much so that wherever a sulphate was capable of detecting this earth, chromate of potash also indicated its presence. Wishing to examine some minerals supposed to contain both strontia and barytes, it occurred to me that the property possessed by a diluted solution of muriate of strontia of not precipitating with chromate of potash, might be made available for analytical purposes. I therefore made a few experiments to ascertain the fitness of this salt as an agent for separating the salts of these earths when dissolved in a large quantity of water. These experiments at first did not afford very exact results; for the precipilated chromate always appeared to indicate rather more barytes than was originally taken: but this was found to be owing to the chromate, like the sulphate of barytes, requiring ignition before weighing, to expel a little water which obstinately adheres to it when dried at low temperatures; this error was entirely obviated by heating the chromate to redness previous to weighing it.

The cause of the error being thus ascertained, 20 grs. of carbonate of strontia and $5 \mathrm{grs}$. of carbonate of barytes were dissolved in dilute muriatic acid; the solution was carefully evaporated to dryness to expel the excess of acid; the dry sait was redissolved in distilled water, and the solution diluted to a pint and a half ; to this was added a dilute solution of chromate of potash, made with transparent crystals, in order to prevent the otherwise possible admixture of sulphate or carbonate. After standing for a short time it was filtered, and the chromate of barytes washed, dried, and ignited; weight 6.53 grs. $=$ 5 grs. of carbonate. The solution and washings were then evaporated to reduce the liquor to a smaller compass, and a solution of sesquicarbonate of ammonia added, which precipitated carbonate of strontia ; this when collected and dried weighed 19.19 grs.

Another experiment, in which the quantity of barytes exceeded that of the strontia, was conducted in a similar manner, with the exception of the employment of less water ( $\frac{3}{4}$ pint) to dissolve the dry salt before the addition of the chromate of potash. In this case there were obtained from $12 \mathrm{grs}$. of carbonate of barytes, and $8 \mathrm{grs}$. of carbonate oi strontia, $15.8 \mathrm{grs}$. of chromate $=12.09 \mathrm{grs}$. of carbonate of barytes, and $7 \cdot 26 \mathrm{grs}$. of carbonate of strontia.

In both the above experiments it will be remarked that there is less carbonate of strontia obtained than was originally taken : this is owing to strontia not being entirely precipitated by a solution of sesquicarbonate of ammonia; for when this salt and muriate of strontia are 
mixed, the former being in excess, the filtered liquor will become slightly turbid on the addition of oxalate of ammonia, and stirring the solution.

In the following experiment, in which 10 grs. of each carbonate were taken, and oxalate substituted for sesquicarbonate of ammonia, the results were chromate of barytes $13.04 \mathrm{grs} .=10 \mathrm{grs}$. of curbonate, and $11.9 \mathrm{grs}$. of oxalate $=10 \mathrm{grs}$. of carbonate of strontia ; thus showing the superiority of oxalate of ammonia as a precipitant for strontia : the only precaution necessary is to have the solution neutral.

Note. Pyroxylic spirit produces a more intense crimson flame with a small quantity of muriate of strontia than alcohol does, and consequently is of greater service as a test for recognising strontia when occurring in minute quantity.

St. Thomas's Hospital,

Feb. 1836.

COMPOSITION OF CARBONATE OF ZINC.-BY MR. J. D. SMITH.

When solutions of sesquicarbonate of ammonia and sulphate of zinc are mixed, a white, bulky, and gelatinous precipitate is produced; this after repeated washings with hot water, by which carbonic acid gas is plentifuliy evolved, falls as a white powder. 80 grs. of this powder lost by ignition $22.5 \mathrm{grs}$., and $81 \mathrm{grs}$. dissolved in a counterpoised bottle of dilute sulphuric acid, lost $12.5 \mathrm{grs}$. of carbonic acid. From these experiments it appears that 80 grs. of this powder are composed of 57.5 grs. oxide of zinc, 12.5 grs. of carbonic acid, and 10 grs. of water; which numbers indicate a compound of $2 \frac{1}{2}$ eqs of oxide of zine, 2 eqs. of water, and 1 eq. of carbonic acid; which may be viewed either as a $\frac{a}{5}$ carbonate of zinc with 4 eqs. of water, or as 1 eq. of hydrated subsesquicarbonate of zinc united to $I$ eq. of hydrate of zinc. Its equivalent number being in former case 280 , in the latter 140 ,

St. 'Tlomas's Hospital,

$$
\begin{array}{cc}
\text { or } 2 \frac{\mathrm{I}}{2} \text { eqs. of oxide of zinc } & 100 \\
1 \text { eq. of carbonic acid } & 22 \\
2 \text { eqs. of water...... } & 18-140 .
\end{array}
$$

Feb. 1836 .

ON RIOLITE, A SUPPOSED BISELENIURET OF ZINC, AND HERRERITE, SUPPOSED TO BE CARBONATE OF TELLURIUM.-BY PIOFESSOR DEL RIO.

An account is given by Mr. Del Rio, in vol. iv. of the Phil. Mag. and Ann., p. 113, of two new minerals found in Mexico; one supposed to be biseleniuret of zinc and sulphuret of mercury, which in honour of Mr. Del Rio I have named Riolite ; the other, considered a biseleniuret of zinc and bisulphuret of mercury, I have named Culebrite, from the place in which it occurs.

By the last mail I have received the following letter from Mr. Del Rio relative to the first of these substances, and to another mineral, supposed to be carbonate of tellurium, which I shall be obliged to the 